\title{
THE STUDY OF MATERIAL CHANGES IN SHOT BLASTING PROCESS
}

The contribution deals with the blasting process from the point of view of degradation phenomena. The interaction of blasting material with the blasted surface causes changes in both blasting material and substrate. In this paper we investigate the wear of various blasting materials and the degradation of the substrate surface. On the basis of the evaluation of studied phenomena in blasting process the classification of upgrading and degrading effects was carried out.

Keywords: upgrading and degrading phenomena, degradation of blasting media, degradation of blasted material

\section{Introduction}

Blasting technology belongs to the mechanical surface machining group. Machining tool, i.e. blasting material, produces upon impact qualitative changes in the surface layers of substrate, forming a typical surface morphology.

Blasted surface cannot be classified, on the basis of its technological origin, within the basis group of mechanically treated surfaces, i.e. as a "new" surface, created by cutting operations, or as a deformed surface created by mechanical working $[1,2,3]$.

Final blasted surface is produced both by the surface layer deformation and by removing a part of substrate material. Blasted surface is multiple-loaded by blasting material; therefore it accumulates plastic deformation. Under the influence of multiple surface loading the surface layers change their dimensions, geometrical characteristics, structural properties, stress state etc. Thermal effects of the blasting process can induce structural changes of substrate surface and subsurface layers. These changes induced mainly by mechanical effects can affect macro-, micro-, or submicroscopic volumes of blasted surface layers.

Impact of blasting material on the blasted substrate produces qualitative changes in both involved subjects, i.e. in blasting material and in substrate.

\section{Substrate degradation in the blasting process}

The influence of the blasting process on the substrate can be separated into upgrading and degrading effects. However, since blasting process is a very complex one, no unanimous classification of various effects is possible. In many cases upgrading effects may be considered also as degrading effects [4]. Character of these effects depends upon the aim and purpose of the surface pre-treatment. Schematic classification of blasting effects on substrate is shown in Fig. 1.

Mechanical surface pretreatment creates suitable surface roughness for perfect anchoring of subsequently applied coatings. Final blasted surface is formed by the deformation of surface and peaks, and by their partial change, in dependence on the blasting angle, see Fig. 2, Fig. 3. Metallographic analysis shows, that during blasting process material is transferred and new configuration of extrusions is formed. When blasting angle is small a cutting (grooving) effect dominates and microchips are formed. For larger blasting angles a forging effect dominates, in dependence on the relation between the substrate and blasting material hardness. Due to intensive deformation processes in surface layers and due to the removal of an intermediate layer a surface with high activity is produced during blasting. This fact contributes significantly to the corrosive resistance of subsequently formed coatings. Real surface enlargement improves the adhesion of coatings on blasted substrates. But new surfaces formed by blasting are characterized by a fast decrease of their activity due to their reaction with the atmosphere. This decrease of surface activity has negative impact to the adhesion of coating applied to these surfaces. Blasting process may be considered as a process for improving mechanical and technological properties of metallic materials. Blasting involves plastic deformation of substrate surface layers, leading to the strengthening of these layers and to the appearance of mainly compressive stresses. This enhances the material resistance to cyclic fatigue. Surface purity is determined by the degree of removing scale, rust products, old coatings and other impurities. In the process of blasting the above-mentioned impurities are removed from the surface (upgrading effect), but, on the other hand, the surface is secondary contaminated by embedded grains, by parts of blasting material adhering to the surface and by free dust particles (degrading effect).

Blasting process is thus accompanied with some degrading effects related to the substrate and to the blasting material. It is

\footnotetext{
* Dušan Kniewald, Janette Brezinová, Anna Guzanová

Deparment of technology and materials, Faculty of Mechanical Engineering, Technical university, Masiarska 74, SK-040 01 Košice,

E-mail: Dusan.Kniewald@tuke.sk, Janette.Brezinova@tuke.sk, anna.guzanova@tuke.sk, Phone: +421-55-6222742
} 


\section{kOMNIKCCle}

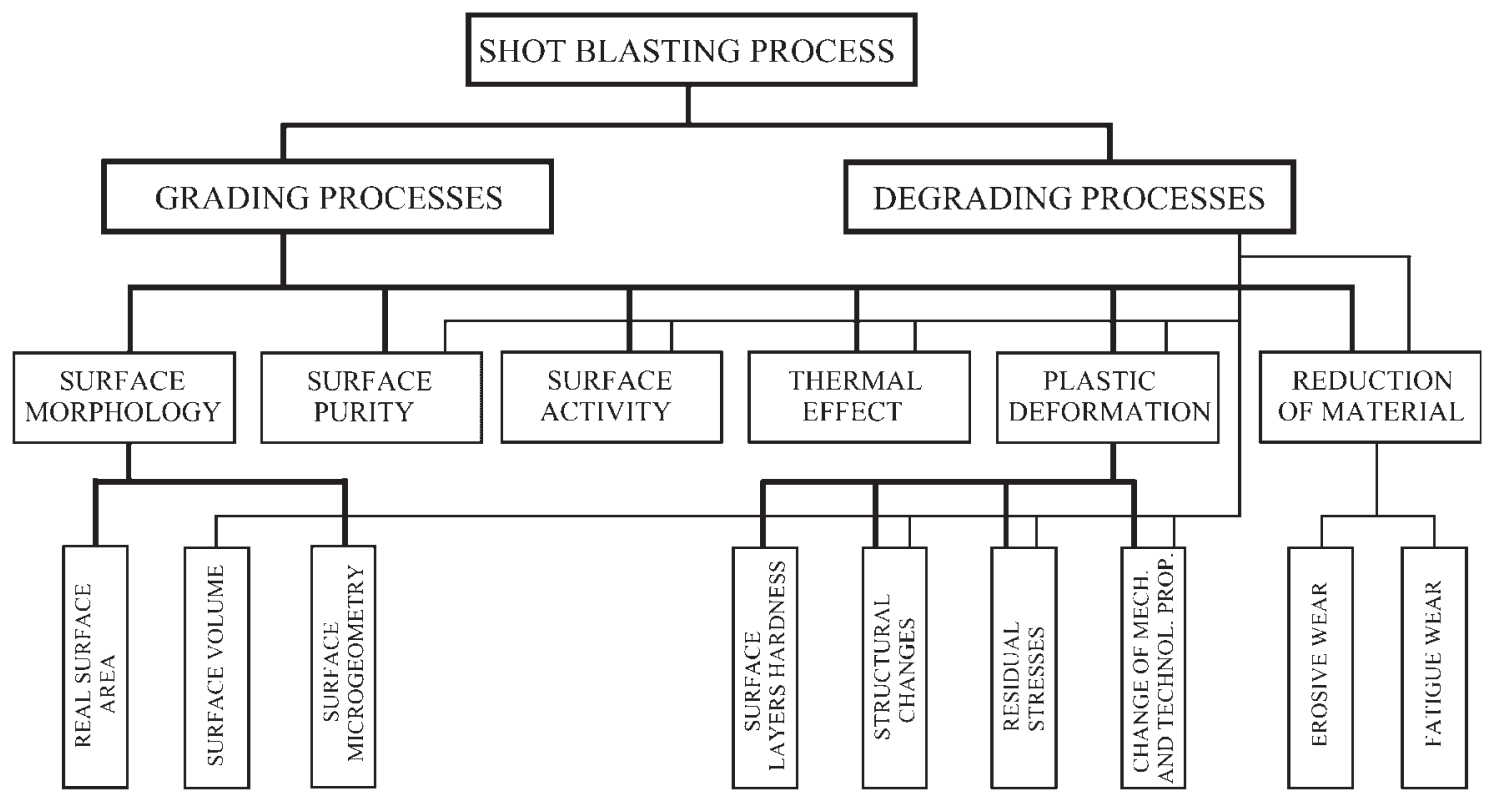

Fig. 1 Schematic classification of blasting effects on substrate [4]

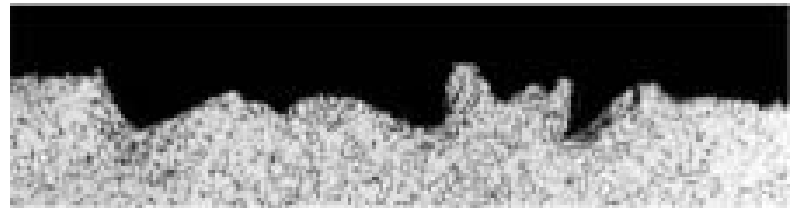

$\alpha=30^{\circ}$

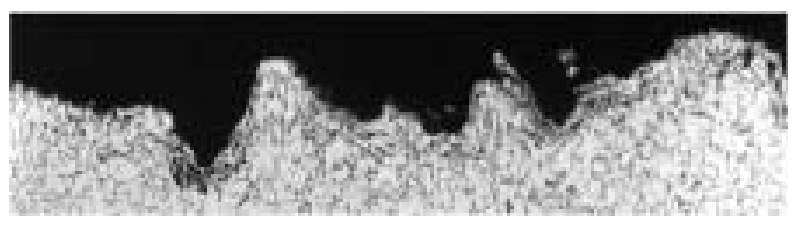

$\alpha=75^{\circ}$

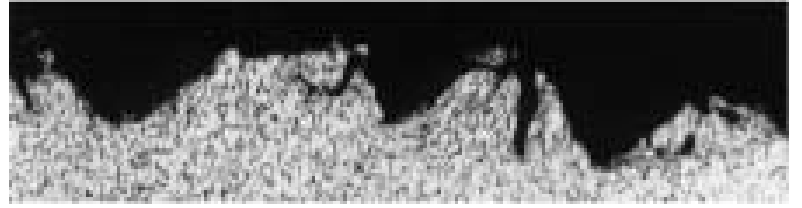

$\alpha=45^{\circ}$

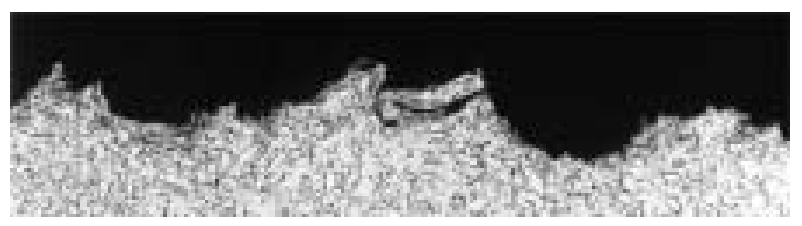

$\alpha=90^{\circ}$

Fig. 2 Cross sections of shot blasted substrate in shot blasting medium direction, when $d_{z D}=0.9 \mathrm{~mm}$ [4]

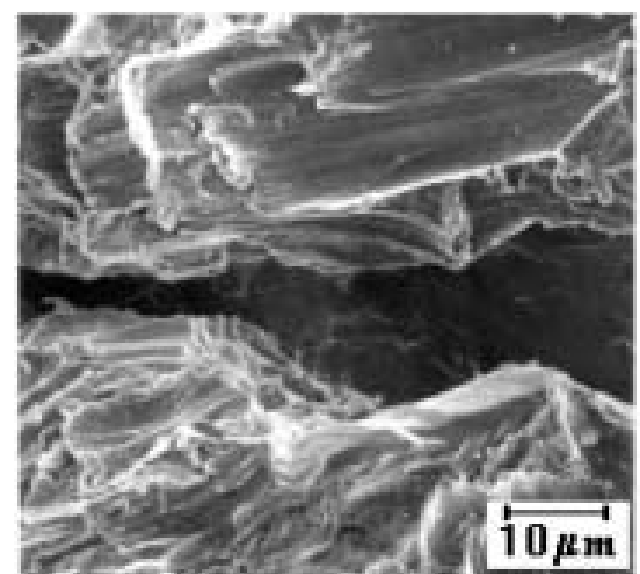

a)

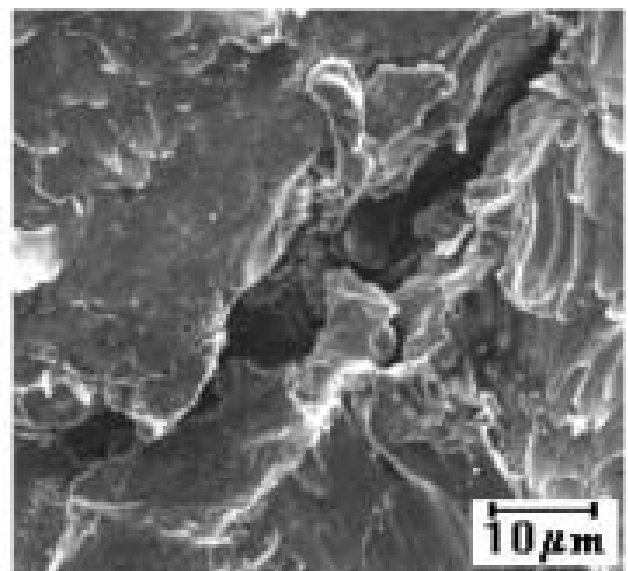

b)

Fig. 3 SEM photos of shot blasted surface when the blasting angle was: a) $\alpha=30^{\circ}$, b) $\alpha=90^{\circ}[4]$ 
necessary to pay proper attention to these effects, according to their significance. During blasting process substrate material is removed in the form of microchips. Removal of rust products and other impurities from the surface may be considered as upgrading effect. However, due to the increasing degree of coverage after multiple impact of blasting material grains the removal of the basis material begins to take place, followed by the surface delamination [4], Fig. 4. Surface layers separation depends probably mainly on defects presence in material. From this point of view this effect may be considered as degrading. Delaminating effect is a result of an incorrect blasting regime, which may be termed as surface "overblasting". Blasting material grains are also cyclically loaded during the blasting process. Change of shape and reduction of grain size by breaking occurs due to repeated loading during blasting. At the same time both substrate and blasting material are subjected to thermal load.
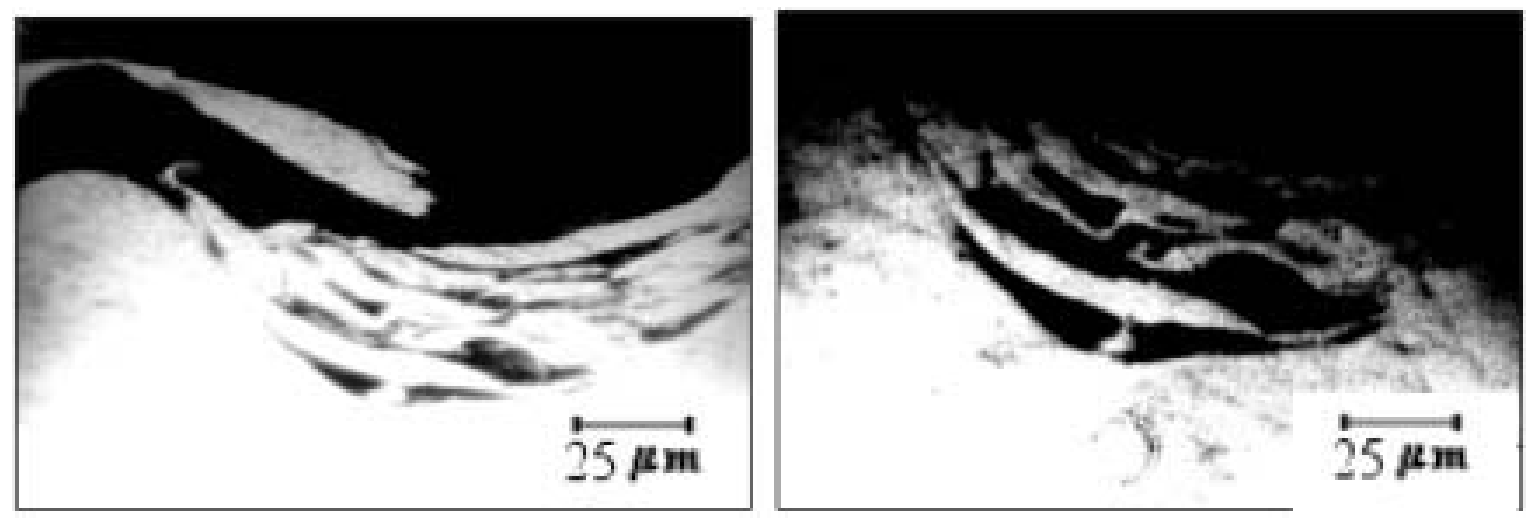

Fig. 4 Surface delamination [4]

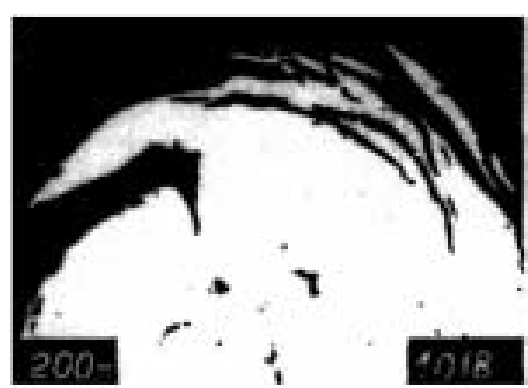

a)

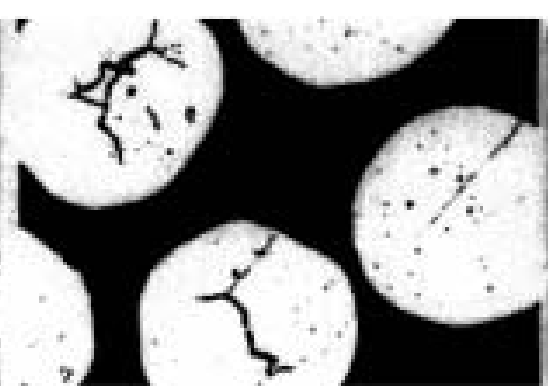

b)
The wearing process of metallic blasting media is characterized as follows [5]:

- cut wire

- rounding and slow abrasion wear,

- intensive blasting media flaking and grain breaking,

- slow wear down to the formation of dust particle, Fig. 5a

- steel shot

- breakdown of double, cavernous and oval grains created by granulation,

- gradual wear down to their total disintegration, Fig. 5b,

- cast iron grit - grain wear by fracturing is very intensive from the beginning of their use, Fig. $5 \mathrm{c}$

Wear of non-metallic blasting materials is characterized by a different wearing mechanism (mainly brittle fracture), resulting from their material characteristics. Tougher and softer blasting

Fig. 5 Blasting material grain wear ( $a$ - cut wire, $b$ - steel shot, $c$ - iron grit) [5]

\section{Blasting material degradation during blasting process}

Periodical use of blasting material in the blasting process induces its intensive wear. The character of this wear is determined by the type of blasting material, the shape and size of its grains, by blasting parameters (grain impact velocity, blasting angle) and by the quality of substrate material. Continuous gradual wear results in the change of blasting material grain size, producing new grain fractions. Wearing mechanism of metal and non-metal blasting materials is different. materials are visibly deformed, hard and brittle materials crumble and break upon their impact on substrate. Wear of non-metallic blasting materials is more intensive when compared with metallic blasting materials, which is evident also from the changes of the blasted substrate appearance. Fig. 6 shows appearance changes of a substrate blasted by mineral blasting material - natural garnet Bohemia with grain size $d_{z D}=0.56 \mathrm{~mm}$ - after the first, tenth and twentieth blasting cycle. 3D pictures of shot blasted surface were obtained by a modified stylus profilometry method [6] 
a)

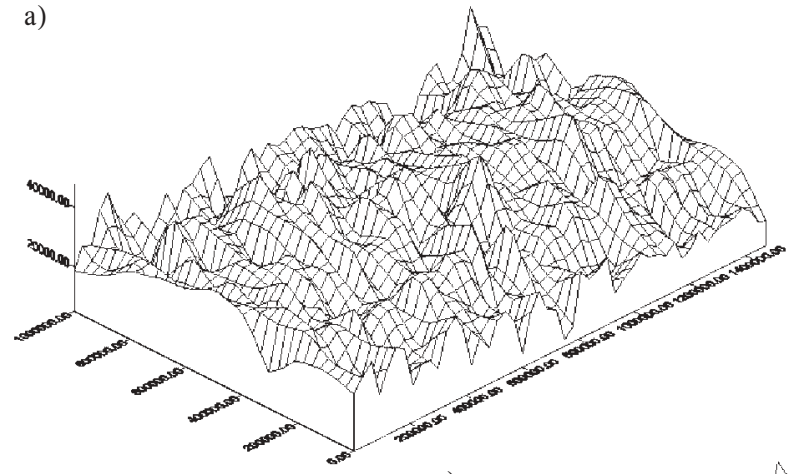

c)

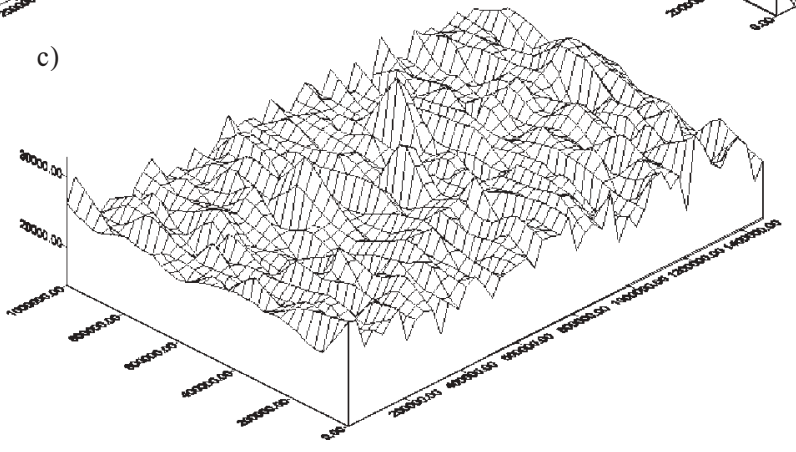

Fig. $63 D$ view of surfaces blasted by: a) GBM $0.56 \mathrm{~mm}$ after the first blasting cycle, b) GBM $0.56 \mathrm{~mm}$ after 10th blasting cycle, c) GBM $0.56 \mathrm{~mm}$ after 20th blasting cycle [6]

$\mathrm{GBM}$ - Garnet Bohemia - $\mathrm{Fe}_{3} \mathrm{Al}_{2}\left(\mathrm{SiO}_{4}\right)_{3} ; \mathrm{HK}$ - Brown Corrundum

Intensive crumbling of non-metallic blasting material causes change and enlargement of the grain size range. Fig. 7 shows the change from monodisperse to polydisperse blasting material (Bohemia garnet and brown corundum with grain size $0.56 \mathrm{~mm}$ ) after $20^{\text {th }}$ blasting cycles.

Blasting material degradation is closely connected with its durability. Durability of blasting materials can be determined by several methods:

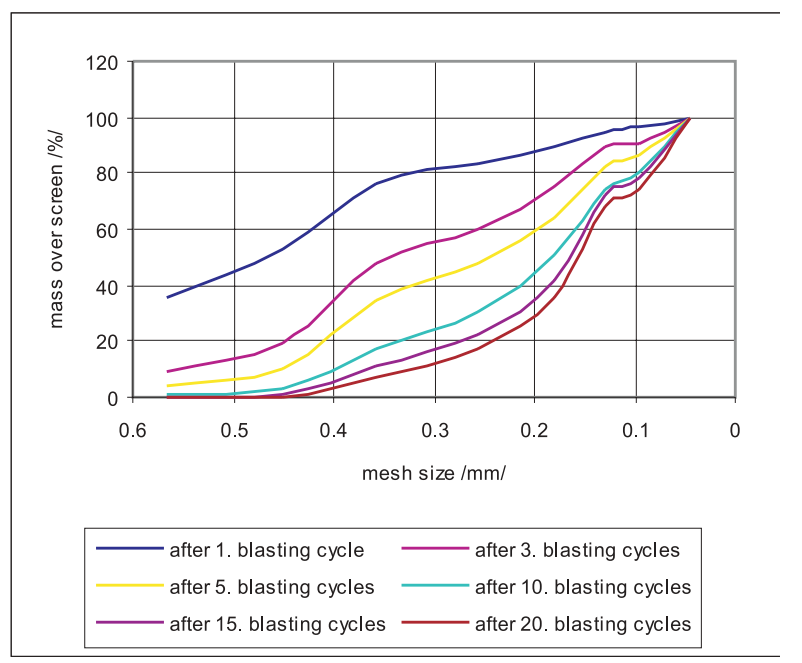

a)

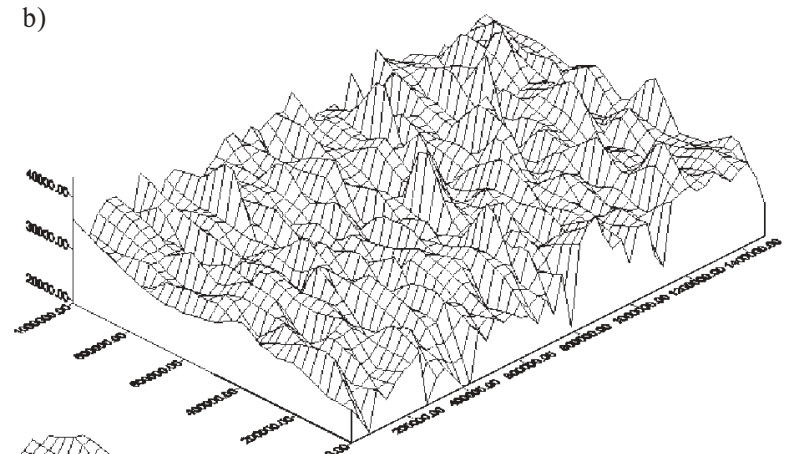

b)

- screening analysis method - this method is based on the detection of the particle portion on nominal screen and it changes in dependence on a number of cycles. Durability of blasting material according to this method is expressed by a number of cycles after which the mass of the blasting medium on the nominal screen is reduced by 50 per cent - marked as $\mathrm{K}_{50}$.

- grain crumbling method - is based on determining the increase of the number of blasting material grains during the blasting process. Durability of blasting material according to this method

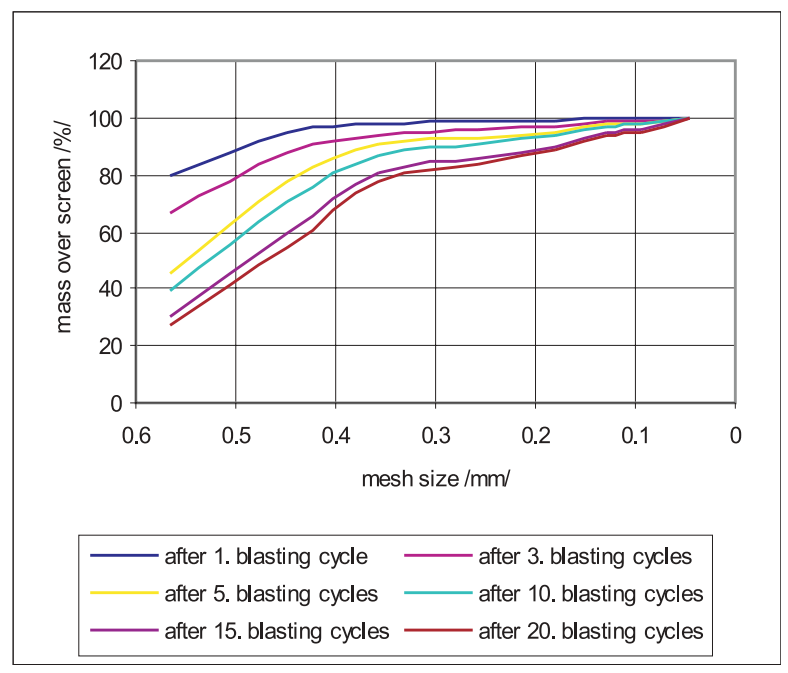

b)

Fig. 7 Cumulative screening curves for a) GBM $0.56 \mathrm{~mm}$ and b) HK $0.56 \mathrm{~mm}$ [6] 
is expressed by a number of blasting cycles after which the number of blasting material grains in a weight unit is doubled. This method is very laborious because the grains have to be manually counted and the loss of grains during the blasting process must be prevented.

- surface roughness method - is based on the fact that the roughness of blasted surface decreases with progressing blasting. Durability of a blasting material according to this method is expressed by a number of cycles after which the surface roughness parameter Ra of the blasted surface decreases by about 15 per cent.

- total wear method - it is a time consuming method, because blasting material is used until it is totally deteriorated. Total wear means that every blasting material grain has certain minimal size - e.g. $0.1 \mathrm{~mm}$.

- blasting material crumbling coefficient $k_{D T P}$ - is expressed as a ratio of the blasting material mass on nominal screen to the total initial blasting material mass after one blasting cycle.

An example of durability determination of metallic blasting materials by screen analysis method for cut wire and steel shot with grain sizes of $0.6 \mathrm{~mm}$ and $1.2 \mathrm{~mm}$ is shown in Fig. 8. Durability of a metallic blasting material is approximately few thousand cycles. Non-metallic blasting materials have substantially lower durability values. In Tab. 1 durability values, determined by four methods, of two types of non-metallic blasting materials with three various grain sizes, are given [6].

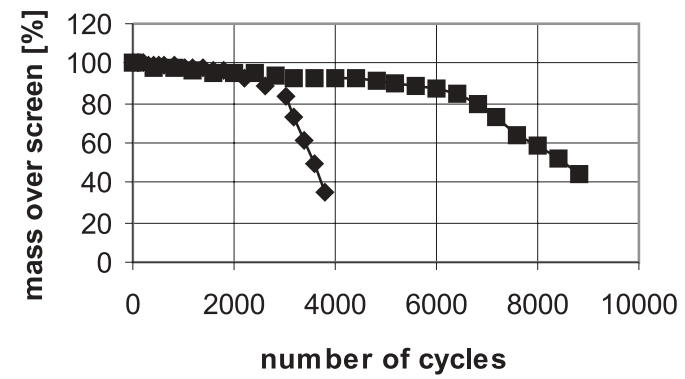

$\longrightarrow$ steel shot $0,6 \mathrm{~mm} \longrightarrow$ cutting w ire $0,6 \mathrm{~mm}$

\section{Conclusions}

Blasting appears to be a suitable technology for the preparation of surface with desirable quality, including impurities removing, achievement of suitable microgeometry and physical - chemical surface properties.

To achieve a technically and economically advantageous use of blasting process, i.e. to achieve desirable surface quality at economically acceptable costs, the blasting process cannot be mechanically applied, but it is always necessary to find the most suitable technical parameters for this technology. This involves the use of new blasting parameters, the blasting parameters and blasting equipment. This is possible only if physical nature of the blasting process is fully understood.

The influence of the blasting process on the substrate can be separated into upgrading and degrading effects. However, since blasting process is a very complex one, no unanimous classification of various effects is possible. In many cases upgrading effects may be considered also as degrading effects. Character of these effects depends upon the aim and purpose of the surface pre-treatment.

Substrate degradation is characterized by surface and subsurface cracks formation, and is at least partially explained by delamination theory. During the blasting process the substrate surface morphology changes, a secondary surface pollution by embedded

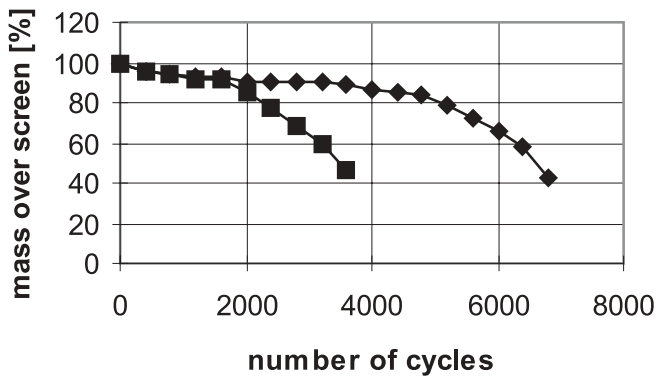

cutting wire $1,2 \mathrm{~mm} \longrightarrow$ steel shot $\mathrm{S} 390$

Fig. 8 Durability curves for steel shot and cut wire with grain size $0.6 \mathrm{~mm}$ a $1.2 \mathrm{~mm} \mathrm{[6]}$

Durability values of blasting materials determined by four methods of durability evaluation.

Tab. 1

\begin{tabular}{|c|c|c|c|c|}
\hline \multirow[t]{2}{*}{ Blasting material } & \multicolumn{4}{|c|}{ Method of durability evaluation. } \\
\hline & $k_{D T P}[-]$ & $\begin{array}{c}\mathrm{K}_{50} \\
\text { [number of cycles] }\end{array}$ & $\begin{array}{c}\text { Total wearing } \\
\text { [number of cycles] }\end{array}$ & $\begin{array}{c}\mathrm{Ra}-15 \% \\
\text { [number of cycles] }\end{array}$ \\
\hline HK $0.56 \mathrm{~mm}$ & 0.8 & 5.4 & 960.8 & 4.9 \\
\hline HK $0.35 \mathrm{~mm}$ & 0.86 & 76.9 & 1591 & 0.5 \\
\hline HK $0.18 \mathrm{~mm}$ & 0.93 & 5012.8 & 3315 & 0.72 \\
\hline GBM 0.56 mm & 0.355 & 0.14 & 135.8 & 0.93 \\
\hline GBM 0.35 mm & 0.69 & 2.29 & 135.8 & 1.1 \\
\hline GBM $0.18 \mathrm{~mm}$ & 0.85 & 6.8 & 189.2 & 0.88 \\
\hline
\end{tabular}


blasting material grains and free dust particles takes place, the surface activity rapidly decreases due to its reaction with the atmosphere together (which has negative impact on the adhesion of subsequently applied coatings), the materials are thermally loaded and undesirable substrate mass reduction also takes place.

Mutual interaction of blasting material with substrate involves complicated processes and mechanisms, leading to blasting material degradation. Wearing mechanisms of metal and non-metal blasting materials are different. Wear of metallic blasting materials is characterised by rounding, intensive flaking and grain breaking, slow wearing down to dust particle creation. Wear of non-metallic blasting materials is characterised mainly by crumbling, resulting from blasting material characteristics. Tougher and softer blasting materials are visibly deformed, hard and brittle materials crumbling and break upon their impact on the substrate.
Blasting material degradation is closely connected with its durability. Durability of blasting materials can be determined by several methods, based on evaluating the changes of various parameters of these materials. Selection of suitable method of durability evaluation depends on the specific application, for which the blasting process is optimised. Modified stylus profilometry makes it possible to obtain 3D views of surfaces blasted by blasting materials in different wearing state. These $3 \mathrm{D}$ view visually document the course of the substrate and blasting material wearing process.

This research was supported by grants VEGA No. 1/9388/02 and 1/9400/02.

\section{References}

[1] KNIEWALD, D. et al.: Study of the blasting process as a substrate pretreatment with respect to subsequent coating process and formation of adhesive joints. Grant research project VEGA No. 1/9388/2002.

[2] BAČOVÁ, V. et al.: Investigation of the properties of plasma sprayed coatings with respect to thermal loads and tribogeneration changes. Grant research project VEGA No. 1/9400/2002.

[3] KNIEWALD, D.: Original knowledge in blasting process. Habilitation thesis. Košice, TU SjF, 1994.

[4] BREZINOVÁ, J.: The study of blasting process regularity from the aspect of degradation phenomena. Academic dissertation. TU SjF Košice, 2003.

[5] TAKÁČ, K.: Influence of blasting regime and structural changes on blasting media durability. Academic dissertation. VŠT SjF Košice, 1969.

[6] GUZANOVÁ, A.: New knowledge in blasting process with ecological blasting media application. Academic dissertation. TU SjF Košice, 2003. 